\title{
Corinne Saminadayar-Perrin, Les discours du journal. Rhétorique et medias au XIX ${ }^{\mathrm{e}}$ siècle (1836-1885)
}

\section{Nicola Ferrari}

\section{OpenEdition}

\section{Journals}

\section{Edizione digitale}

URL: http://journals.openedition.org/studifrancesi/9613

DOI: 10.4000/studifrancesi.9613

ISSN: 2427-5856

\section{Editore}

Rosenberg \& Sellier

\section{Edizione cartacea}

Data di pubblicazione: 1 décembre 2007

Paginazione: 685

ISSN: 0039-2944

\section{Notizia bibliografica digitale}

Nicola Ferrari, «Corinne Saminadayar-Perrin, Les discours du journal. Rhétorique et medias au xix siècle (1836-1885)», Studi Francesi [Online], 153 (LI | III) | 2007, online dal 30 novembre 2015, consultato il 13 janvier 2021. URL: http://journals.openedition.org/studifrancesi/9613 ; DOI: https://doi.org/10.4000/ studifrancesi.9613

Questo documento è stato generato automaticamente il 13 janvier 2021.

\section{(c) (i) () $\Theta$}

Studi Francesi è distribuita con Licenza Creative Commons Attribuzione - Non commerciale - Non opere derivate 4.0 Internazionale. 


\title{
Corinne Saminadayar-Perrin, Les discours du journal. Rhétorique et medias au XIX siècle (1836-1885)
}

\author{
Nicola Ferrari
}

\section{NOTIZIA}

CORINNE SAMINADAYAR-PERRIN, Les discours du journal. Rhétorique et medias au XIX siècle (1836-1885), Publications de l'Université de Saint-Étienne, 2007, pp. 372.

1 L'invito a una manifestazione culturale rivolto, distintamente, a letterati e giornalisti non avrebbe stupito nessuno agli inizi del Novecento. Ancora alla metà del secolo diciannovesimo in Francia, invece, questa distinzione avrebbe, per lo meno, fatto sorridere: come chi avesse opposto cani a bassotti (perché non tutti i cani sono bassotti, ma certo tutti i bassotti sono cani). Nel progressivo spegnersi di questo sorriso si conclude il romanzo del giornalista letterato, che usa la scrittura pubblicistica come trampolino di lancio verso altre carriere, che sospende la sua coscienza tra la prostituzione della penna e l'esercizio di una nuova magistratura politica, indipendente dalle istituzioni. Della storia di sperimentazioni, metamorfosi e transizioni del giornalismo moderno francese - dal 1836 della fondazione della Presse agli anni Ottanta dell'Ottocento, quando, in concomitanza con l'affaire Dreyfuss, si compie il processo di professionalizzazione del giornalista e insieme si definisce incontrovertibilmente il sopravanzamento della vocazione informazionale della stampa su tutti le sue precedenti dimensioni politiche e letterarie -, il saggio di Saminadayar-Perrin offre una significativa analisi tagliata prospetticamente sulle relazioni tra le moderne pratiche discorsive del giornalismo e le antiche tradizioni dell'eloquenza classica. Nel gioco complesso di riflesso e parassitismo, viene acutamente indagato l'impatto della stampa sull'impianto retorico nelle principali forme di spettacolo della parola del diciannovesimo secolo (dalle assai istituzionalizzate dell'assemblea parlamentare, 
dell'Académie, del tribunale fino alle derive da strada di imbonitori e saltimbanchi). Il discorso giornalistico rappresenta una rivoluzione comunicazionale che, radicalmente lontana nell'esito finale dall'antico modello oratorio, mantiene però quell'antico paradigma discorsivo come riferimento ossessivo per tutto il suo sviluppo ottocentesco. La scrittura pubblicistica riflette tutte le pratiche contemporanee del discorso, rivaleggiando con l'oratoria politica, accademica, giuridica nel momento stesso in cui la mima, riproduce, amplifica, drammatizza, rimette in scena, insomma, riportandone non solo i contenuti di inventio e le pratiche di dispositio, ma analizzandone e ricreandone tutto l'apparato rituale di actio comunicativa (la scenografia). In questa complessa relazione saprofita, il discorso del giornale non solo fagocita e deforma le forme oratorie di spettacolo della parola, attraverso la loro pubblicizzazione mediatica (che ne travolge il contesto enunciativo), ma, paradossalmente, proprio nel suo tentativo di resuscitare 'un'economia del discorso vivente' congiura in maniera definitiva alla mummificazione dell'eloquenza in testo. In ultima analisi, nell'arco storico esaminato, si osserva come la prossimità dei discorsi giornalistico e oratorio permetta al primo di vampirizzare l'ordine tradizionale (orale e retorico) del secondo, compiendone l'esaurimento e segnando il definitivo passaggio dalla concezione orale della letteratura-discorso, interattiva e sociale, alla dimensione scritta della letteratura-testo completamente autonomizzata e autoreferenziale, merce il cui valore di scambio sopravanza ogni funzione comunicativa. Da questa considerazione discende che lo studio dell'eloquenza nella stampa ottocentesca permette di dimostrare la parte del discorso pubblicistico nella ricerca di un ruolo pubblico, di uno spazio di intervento intellettuale per lo scrittore spodestato nella crisi letteraria postromantica. Alla ricchezza dei dati esaminati e alla convincente chiarezza dell'impianto espositivo, il saggio consegna il proposito di offrirsi come contributo a un rinnovamento della storia letteraria chiamata a divenire, infine, generale storia della comunicazione umana. Ma questo auspicato orizzonte semiotico-sociologico allargato corre i rischi di un insoddisfacente impoverimento, se il senso si vuole, riduzionisticamente, come assorbimento completo (o asservimento teoretico) dello specifico letterario. Leggendo le riflessioni analitiche del saggio insieme alle (soltanto evocate ma folgoranti e riassuntive) rappresentazioni narrative della stampa contemporanea in Balzac e Zola, se ne può trovare indubitabile conferma. 